\title{
Disease dynamics of Montipora white syndrome within Kaneohe Bay, Oahu, Hawaii: distribution, seasonality, virulence, and transmissibility
}

\author{
G. S. Aeby ${ }^{1, *}$, M. Ross $^{1,2}$, G. J. Williams ${ }^{3}$, T. D. Lewis ${ }^{1,4}$, T. M. Work ${ }^{5}$ \\ ${ }^{1}$ Hawaii Institute of Marine Biology, Kaneohe, Hawaii 96744, USA \\ ${ }^{2}$ Department of Zoology, University of Hawaii, Honolulu, Hawaii 96822, USA \\ ${ }^{3}$ School of Biological Sciences, Victoria University of Wellington, Wellington, New Zealand \\ ${ }^{4}$ US Fish and Wildlife Service, Dexter National Fish Hatchery \& Technology Center, Dexter, New Mexico 88230, USA \\ ${ }^{5}$ US Geological Survey, National Wildlife Health Center, Honolulu Field Station, Honolulu, Hawaii 96850, USA
}

\begin{abstract}
We report on an investigation of Montipora white syndrome (MWS), which is a coral disease reported from Hawaii, USA, that results in tissue loss. Disease surveys of Montipora capitata within Kaneohe Bay (Oahu) found colonies that were affected by MWS on 9 reefs within 3 regions of Kaneohe Bay (south, central, north). Mean MWS prevalence ranged from 0.02 to $0.87 \%$ and average number of MWS cases per survey site ranged from 1 to 28 colonies. MWS prevalence and number of cases were significantly lower in the central region as compared to those in the north and south regions of Kaneohe Bay. There was a positive relationship between host abundance and MWS prevalence, and differences in host abundance between sites explained $\sim 27 \%$ of the variation in MWS prevalence. Reefs in central Kaneohe Bay had lower M. capitata cover and lower MWS levels. MWS prevalence on reefs was neither significantly different between seasons (spring versus fall) nor among 57 tagged colonies that were monitored through time. MWS is a chronic and progressive disease causing $M$. capitata colonies to lose an average of $3.1 \%$ of live tissue $\mathrm{mo}^{-1}$. Case fatality rate was $28 \%$ after 2 yr but recovery occurred in some colonies (32\%). Manipulative experiments showed that the disease is acquired through direct contact. This is the first study to examine the dynamics of MWS within Hawaii, and our findings suggest that MWS has the potential to degrade Hawaii's reefs through time.
\end{abstract}

KEY WORDS: Montipora white syndrome - Disease prevalence $\cdot$ Virulence $\cdot$ Disease transmission $\cdot$ Kaneohe Bay · Hawaii

Resale or republication not permitted without written consent of the publisher

\section{INTRODUCTION}

Coral reefs worldwide are threatened by increasing anthropogenic stressors, particularly overfishing and the problems associated with global climate change (Knowlton 2001, Gardner et al. 2003, Hughes et al. 2003, Pandolfi et al. 2005, Carpenter et al. 2008). Coral disease is recognized as another problem causing the degradation of reefs, which is demonstrated by a global increase in the numbers of coral diseases, coral species affected and disease outbreaks (Harvell et al. 1999, Green \& Bruckner 2000, Ward \& Lafferty 2004, Sutherland et al. 2004). This is especially true in the
Indo-Pacific, where coral disease has recently been recognized as a problem (Willis et al. 2004, Aeby 2005, Sussman et al. 2009, Vargas-Angel 2009). Disease processes are complex and dynamic, and the factors underlying the increasing levels of coral disease remain unclear. Environmental stress, novel pathogens and human impacts have all been implicated (Harvell et al. 1999, Green \& Bruckner 2000); however, a lack of basic information on disease processes is hampering efforts to understand emerging diseases.

Damage to coral reef ecosystems from diseases varies depending on the degree of host specificity and disease virulence. For example, some diseases, e.g. 


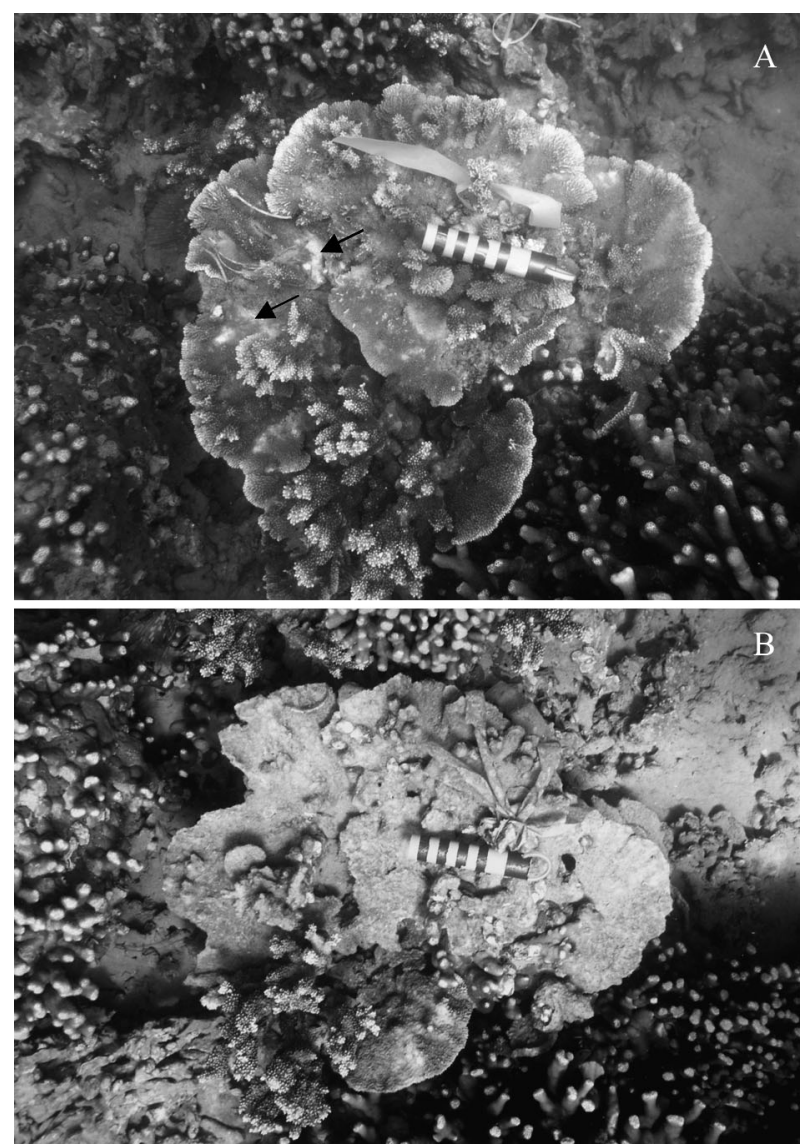

Fig. 1. Montipora capitata. (A) Colony in Kaneohe Bay, Oahu, Hamaii, infected with Montipora white syndrome (MWS), photographed in September 2006. Black arrows: multi-focal areas of tissue loss from the disease. (B) The same colony showing significant colony mortality due to MWS after $1 \mathrm{yr}$ (August 2007). Scale bars shown in (A) and (B): each narrow stripe $=1 \mathrm{~cm}$

growth anomalies (Bak 1983, Yamashiro et al. 2000) or Porites trematodiasis (Aeby 1991, 1992), reduce coral growth or reproduction, whereas other diseases, e.g. the white syndromes reported from the Indo-Pacific, result in partial or total colony mortality (Willis et al. 2004, Aeby 2005, Roff et al. 2006, Sussman et al. 2009). Other diseases affect a single dominant coral genus or species and thus have the potential to shift coral community structure. In the Caribbean, Acropora serratiosis exclusively affects $A$. palmata, and has contributed to its decline and subsequent listing as an endangered species (Patterson et al. 2002, Sutherland et al. 2004).

Baseline disease surveys have been conducted throughout the Hawaiian Archipelago, with 17 coral diseases having been reported (Aeby 2006, Friedlander et al. 2008). However, little is known about the etiology, ecology or pathogenesis of these different coral diseases, with the exception of Porites trematodiasis, which has been extensively studied (Aeby 1991, 1992, 1998, 2002, 2003, 2007). Montipora white syndrome (MWS) is a disease that results in tissue loss (Fig. 1a). It has been reported to occur throughout the Hawaiian archipelago and was found to be particularly prevalent in Kaneohe Bay, Oahu (Aeby 2006, Friedlander et al. 2008). However, nothing is known about the ecology of MWS, making it difficult to evaluate the effect this disease might have on Hawaiian reefs. The objectives of this study were to (1) examine the spatial distribution and prevalence of MWS throughout Kaneohe Bay, (2) investigate seasonal variation in disease prevalence, (3) examine virulence (degree of harm to the host), and (4) determine transmissibility through manipulative experiments.

\section{MATERIALS AND METHODS}

Study site. Kaneohe Bay, which is located on the windward (eastern) side of Oahu, Hawaii, USA, is a complex estuarine system with a large barrier coral reef and numerous patch and fringing reefs (www. pmel.noaa.gov/co2/coastal/kbay/). These reefs are characterized by extensive shallow reef flats and steep reef slopes that extend to a depth of $\sim 10 \mathrm{~m}$. Coral cover is composed predominantly of large thickets of Porites compressa Dana, 1846, that are interspersed with colonies of Montipora capitata Dana, 1846 (Jokiel 1987). Kaneohe Bay has a history of reduced water quality, with periodic episodes of terrestrial runoff (Cox et al. 2006) and sewage outfalls (prior to 1977; Maragos et al. 1985, Hunter \& Evans 1995).

Distribution, prevalence and seasonality of MWS. Three patch reefs within each region of Kaneohe Bay (south, central, north) were surveyed in September 2006 (Fig. 2) (total $\mathrm{n}=9$ reefs). Two $25 \mathrm{~m}$ transect lines were laid end to end, separated by $\sim 3 \mathrm{~m}$, along the upper slope of each patch reef. One diver enumerated all Montipora capitata colonies whose center fell within a $1 \mathrm{~m}$ wide belt on each side of the line $(25 \times$ $2 \mathrm{~m})$. A second diver measured coral cover using the point-intercept method, recording substrate type at $50 \mathrm{~cm}$ intervals along the transect and surveying a wider area along the belt transect $(25 \times 6 \mathrm{~m})$ for colonies exhibiting signs of MWS. In order to determine whether disease prevalence varied between seasons, surveys were repeated in May 2007. The average percent coral cover, colony density, number of MWS affected colonies, and prevalence of MWS were determined from diver surveys.

Rate of tissue loss and virulence (extent of damage) of MWS. To determine the rate of tissue loss due to MWS, 57 individual coral colonies having signs of MWS were tagged and photographed with a digital 


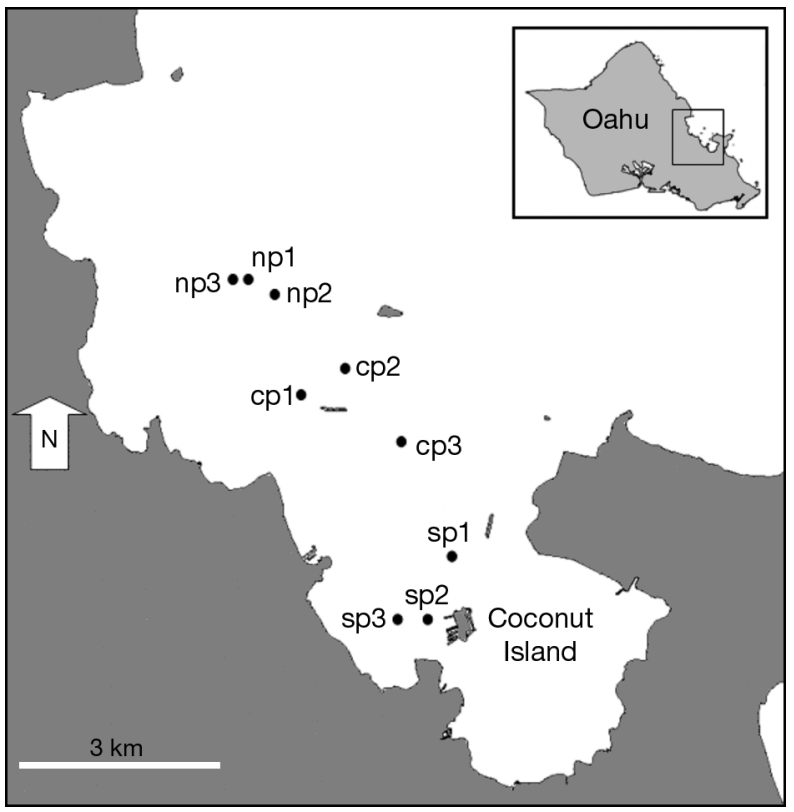

Fig. 2. Kaneohe Bay, Oahu, Hawaii. The 9 reefs surveyed for Montipora white syndrome (MWS) are shown. np: north patch reef; cp: central patch reef; sp: south patch reef

camera every 1 to 2 mo from September 2006 to August 2007. A follow-up survey was conducted in August 2008. All marked colonies were located on the fringing reef surrounding Coconut Island, which is located in the southern end of Kaneohe Bay. The irregular, 3-dimensional shapes of the coral colonies prevented the use of digital image analysis for calculating the rate of tissue loss. Instead, a semi-quantitative estimate of tissue loss was used. Colonies were scored in situ as to the percentage of the colony surface that appeared diseased, healthy or dead.

Transmissibility of MWS. Manipulative experiments were conducted to determine whether MWS is transmissible through direct contact or indirectly through the water. Experiments were conducted under static conditions using a paired design in which 2 aquaria (experimental and control) were used, each containing 2 fragments of healthy Montipora capitata. In the experimental tank, an infected fragment was placed in direct contact with 1 healthy fragment (direct transmission) and the other healthy fragment was $\sim 10 \mathrm{~cm}$ away (waterborne transmission). In the control aquaria, the diseased fragment was replaced with an additional healthy fragment to control for lesions created by coral to coral aggressive interactions. Photographs of all fragments were taken at Day 0 and once a week thereafter. All fragments were examined daily for signs of acute to subacute tissue loss. Water quality was maintained through partial water changes twice weekly and each aquarium had a bubbler to create water motion. Aquaria were held under natural light and ambient temperatures ranging from 24 to $26^{\circ} \mathrm{C}$. Five paired experimental runs were completed.

Statistics. The data did not conform to a normal distribution, even with transformation; hence, data were analyzed using a permutational multivariate analysis of variance (PERMANOVA) using PERMANOVA+ for PRIMER (Anderson et al. 2008). The statistical assessment of permuted p-values carries more weight than arbitrary thresholds determined from probability tables. This multivariate technique was used to carry out a univariate ANOVA on non-normal data using tests by permutation. Two factors were tested: season (Fall 2006 and Spring 2007) and region of the bay (north, central, south). Both factors were considered to be crossed with each other and were therefore treated as fixed. The effect of each factor, and their interaction, were tested using unrestricted random permutations of the raw data, Type III (partial) sums of squares, and zero-adjusted Bray-Curtis similarity matrices (Clarke et al. 2006). Two response variables were tested: MWS prevalence (percentage of the population displaying the disease) and the number of MWS cases per site. This was done to account for any differences that might have occurred due to the derived nature of the prevalence calculations.

The proportion of variability that is explained by any differences in depth, density of Montipora colonies (no. $\mathrm{m}^{-2}$ ), and Montipora percentage cover was investigated using a nonparametric distance-based linear model (DISTLM) in PERMANOVA+. Models were based on 4999 random permutations of the raw data and zero-adjusted Bray-Curtis similarity matrices. The 3 predictor variables were analyzed individually for their relationship with both MWS prevalence and number of cases, ignoring all other predictor variables (marginal tests). The predictors were then subjected to a stepwise selection procedure and Akaike's information criterion (Akaike 1973) with a second-order bias correction was applied (AICc) (Hurvich \& Tsai 1989) to develop a model for the MWS data (sequential/conditional tests).

\section{RESULTS}

\section{Distribution, prevalence and seasonality of MWS}

MWS was found in all surveyed regions of Kaneohe Bay, with all 9 reefs having colonies with signs of the disease (frequency of occurrence $=100 \%$ ) (Table 1 ). Average MWS prevalence (all surveys combined) was $0.23 \pm 0.09 \%$ SE (range 0.02 to $0.87 \%$ ). The number of MWS cases per survey site $\left(300 \mathrm{~m}^{2}\right)$ ranged from 1 to 28 colonies. There was a significant effect of region on 
Table 1. Mean host (Montipora capitata) abundance and Montipora white syndrome (MWS) levels at 9 reefs surveyed in Kaneohe Bay, Oahu, Hawaii, in Fall 2006 and Spring 2007. There was no significant difference in host abundance or MWS levels between survey dates; hence, data from surveys were combined within each site. See Fig. 2 for site abbreviations and locations

\begin{tabular}{|lccrcc|}
\hline Site & $\begin{array}{c}\text { Depth } \\
(\mathrm{m})\end{array}$ & $\begin{array}{c}\text { M. capitata } \begin{array}{c}\text { coundance } \\
\text { No. of } \\
\text { colonies } \mathrm{m}^{-2}\end{array} \\
\text { Cover } \\
(\%)\end{array}$ & $\begin{array}{c}\text { MWS levels } \\
\text { No. of } \\
\text { cases }\end{array}$ & $\begin{array}{c}\text { Prevalence } \\
(\%)\end{array}$ \\
\hline South & & & & & \\
sp1 & 1.5 & 5.3 & 11.8 & 6.0 & 0.2 \\
sp2 & 3.0 & 5.2 & 29.0 & 27.5 & 0.9 \\
sp3 & 2.1 & 5.9 & 29.5 & 14.5 & 0.4 \\
Central & & & & & \\
cp1 & 1.5 & 5.1 & 4.0 & 1.0 & 0.0 \\
cp2 & 2.4 & 3.2 & 2.5 & 0.5 & 0.0 \\
cp3 & 2.4 & 5.7 & 10.3 & 3.0 & 0.1 \\
North & & & & & \\
np1 & 3.7 & 7.5 & 6.4 & 4.5 & 0.1 \\
np2 & 4.0 & 5.4 & 15.2 & 6.0 & 0.2 \\
np3 & 3.4 & 5.6 & 19.6 & 5.5 & 0.2 \\
\hline
\end{tabular}

Table 2. A 2-way crossed permutational multivariate analysis of variance (PERMANOVA) for prevalence and number of cases of Montipora white syndrome between Fall 2006 and Spring 2007 within 3 regions (north, central, south) of Kaneohe Bay, Oahu, Hawaii. *Significant differences, with a Monte Carlo (MC) permutational p-value <0.05; ns: not significant

\begin{tabular}{|lrcccc|}
\hline \multirow{2}{*}{ Source } & df & \multicolumn{3}{c|}{$\begin{array}{c}\text { Prevalence } \\
F\end{array}$} & \multicolumn{2}{c|}{$\begin{array}{c}\text { No. of cases } \\
\end{array}$} & & p(MC) & $F$ & $\mathrm{p}(\mathrm{MC})$ \\
\hline Season & 1 & 0.13 & $\mathrm{~ns}$ & 1.04 & $\mathrm{~ns}$ \\
Region & 2 & 4.14 & $0.01^{*}$ & 4.98 & $<0.01^{*}$ \\
Season $\times$ Region & 2 & 0.66 & $\mathrm{~ns}$ & 1.45 & $\mathrm{~ns}$ \\
Residual & 12 & & & & \\
Total & 17 & & & & \\
& & & & & \\
\hline
\end{tabular}

both MWS prevalence (pseudo $F_{2,12}=4.14, \mathrm{p}=0.01$ ) and number of cases (pseudo $F_{2,12}=4.98, \mathrm{p}=<0.01$ ) (Table 2). MWS prevalence and number of cases were significantly lower in the central region than in both the north $(t=2.59, \mathrm{p}=0.04 ; t=3.24, \mathrm{p}=0.01)$ and south $(t=2.02, \mathrm{p}=0.04 ; t=2.19, \mathrm{p}=0.02)$ (Fig. 3). There was a positive relationship between host abundance and MWS (Fig. 4) and Montipora cover alone formed the optimal model for both MWS prevalence $(\mathrm{AICc}=$ 132.4, pseudo $F=5.84, \mathrm{p}=0.005$ ) and number of cases (AICc $=131.0$, pseudo $F=6.05, \mathrm{p}=0.005$ ), explaining 26.7 and $27.4 \%$ of the variability in the data sets, respectively.

There was no significant effect of season, and the interaction between season and region, on either MWS prevalence or number of cases (Table 2) was also
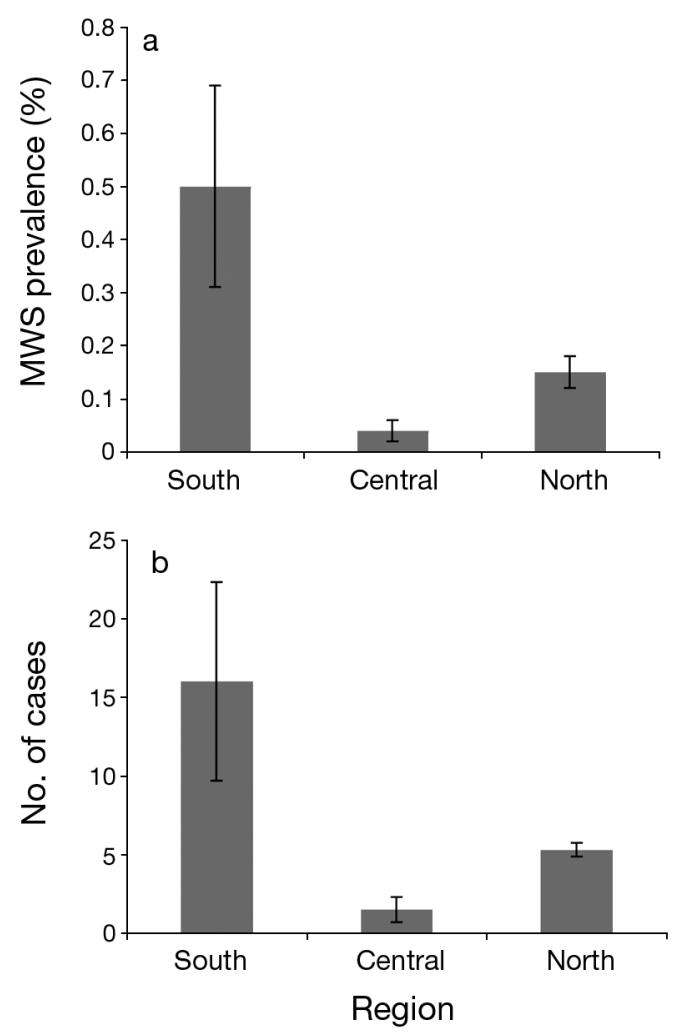

Fig. 3. Mean prevalence $( \pm \mathrm{SE})$ and no. of cases $( \pm \mathrm{SE})$ of Montipora white syndrome (MWS) in different regions of Kaneohe Bay, Oahu, Hawaii. Three patch reefs were surveyed in each region in Fall 2006 and Spring 2007. Data reflect all survey dates combined

insignificant. Mean MWS prevalence in September 2006 was $0.27 \pm 0.08 \%$ SE as compared to an average prevalence of $0.35 \pm 0.13 \%$ SE in May 2007 .

\section{Rate of tissue loss and extent of damage from MWS}

Between September 2006 and August 2007, the average rate of total tissue loss on individual colonies $(\mathrm{n}=57)$ ranged from $+1 \%$ (regrowth of dead areas) to $100 \%$ (mortality) (avg: $-36.7 \pm 3.6 \% \mathrm{SE}$ ). In some cases, the disease appeared to stop (no visual signs) and then restarted in subsequent months. Disease progression was usually slow but steady, with an average of $3.1 \pm 0.3 \% \mathrm{SE}$ of the tissue being lost on colonies per month (Fig. 1b). As tissue was lost from the coral colony, invasion by algae and other boring organisms occurred, eroding the coral skeleton, which in 2 cases resulted in the complete collapse of the colony. No seasonality was evident, with diseased colonies being consistently present throughout the year (Table 3). Case fatality rate from disease for the first year was $7.0 \%$ of the tagged colonies. The resurvey in August 


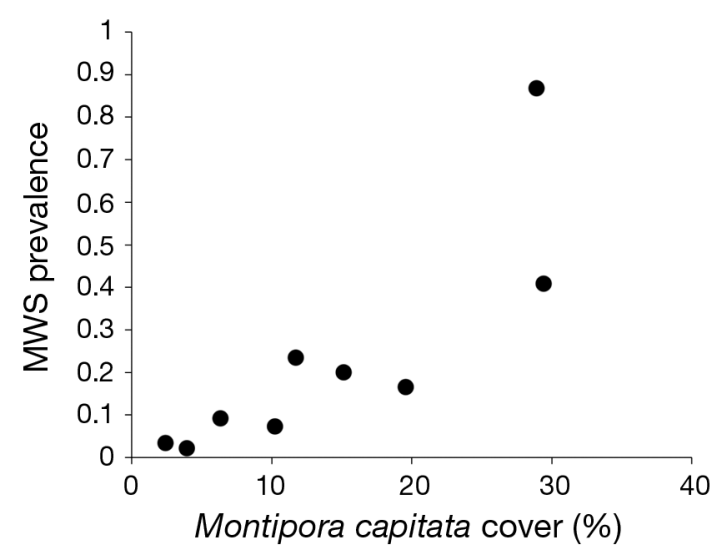

Fig. 4. Relationship between host coral cover and Montipora white syndrome (MWS) prevalence. Nine patch reefs within Kaneohe Bay, Oahu, Hawaii, were surveyed in Fall 2006 and Spring 2007. Data reflect means from each site for all sampling dates combined

Table 3. Prevalence of Montipora white syndrome (MWS) on tagged Montipora capitata colonies monitored through time $(\mathrm{n}=57)$

\begin{tabular}{|lc|}
\hline Month & MWS prevalence (\%) \\
\hline September & 61.8 \\
November & 68.8 \\
February & 67.9 \\
March & 74.1 \\
April & 81.5 \\
May & 79.6 \\
June & 84.6 \\
July & 55.8 \\
August & 82.7 \\
\hline
\end{tabular}

2008 revealed additional mortality, with total case fatality due to MWS between 2006 and 2008 being $28 \%$ of the 57 colonies. Recovery from MWS was also evident in 2008, with $32 \%$ of the colonies that were initially identified to be with MWS in September 2006 showing no disease signs and a regrowth of tissue.

\section{Transmissibility of MWS}

MWS was found to be transmissible through direct contact between MWS affected and healthy coral fragments. Disease transmission between a diseased and a healthy fragment occurred in $100 \%$ of the experimental runs $(n=5)$, whereas no signs of tissue loss occurred in the control aquaria $(n=5)$. The time required for transmission to occur ranged from 23 to $51 \mathrm{~d}$. Lesions appeared as diffuse tissue loss similar to the leading edge of MWS lesions in the field. Tissue loss was not observed on nontouching coral fragments within treatment aquaria. Hence, no waterborne disease transmission was evident within the timeframe of the experiments.

\section{DISCUSSION}

This is the first report on the dynamics of MWS in Hawaii. MWS was found throughout Kaneohe Bay, which showed regional differences in MWS levels (prevalence and number of cases). Patch reefs in the central region of Kaneohe Bay had significantly lower levels of MWS than those in the north and south ends of the Bay. Regional differences in MWS levels were partly explained by the significant relationship that was observed between MWS and host (Montipora capitata) abundance. Reefs in central Kaneohe Bay had lower $M$. capitata cover, and hence, lower MWS levels. This is consistent with numerous other host-pathogen systems in which a positive relationship occurs between host abundance and disease prevalence (Anderson \& May 1979, Lafferty \& Holt 2003, Poteet 2006) including coral disease (Bruno et al. 2007, Haapkyla et al. 2009, Myers \& Raymundo 2009). Interestingly, we found that host cover was a much better explanatory variable for MWS abundance than our direct measure of coral host density (colony counts). The sizes of individual coral colonies can vary greatly from a diameter of $<5 \mathrm{~cm}$ to $>1 \mathrm{~m}$; therefore, individual colony counts are not necessarily the best indicator of host abundance. We found similar $M$. capitata densities in all regions of Kaneohe Bay but significantly different estimates of $M$. capitata cover. For coral disease studies, it may be prudent to consider coral colony sizes when interpreting colony density data.

The frequency of occurrence and average prevalence of MWS within Kaneohe Bay were higher than those found on other reefs in the main or northwestern Hawaiian Islands (Friedlander et al. 2008). Kaneohe Bay has a history of reduced water quality, which could have influenced MWS prevalence as some coral diseases are influenced by environmental stressors. Voss \& Richardson (2006) found that nutrient enrichment enhanced the progression of black band disease (BBD) on corals, and Kaczmarsky et al. (2005) found that BBD and white plague type II were both significantly more prevalent on reefs that were closest to sewage effluents as compared to similar reefs that were situated upstream from the same sewage outfall. Water quality, however, does not affect all coral diseases in the same manner. Page \& Willis (2006) found no relationship between the prevalence of BBD and terrestrial influences on reefs on the Great Barrier Reef (GBR).

Increased seawater temperatures can result in increased host susceptibility to disease as well as in- 
creased pathogen virulence (Harvell et al. 2007). Positive relationships between disease prevalence and/or incidence and temperatures have been found for BBD in the Western Atlantic (Edmunds 1991, Bruckner \& Bruckner 1997a, Kuta \& Richardson 2002) and on the GBR (Boyett et al. 2007), white plague in Puerto Rico (Bruckner \& Bruckner 1997b), atramentous necrosis in Australia (Jones et al. 2004), white syndrome along the GBR (Bruno et al. 2007), and dark spot syndrome in Columbia (Gil-Agudelo \& Garzón-Ferreira 2001). However, for MWS within Kaneohe Bay, there was no evidence of seasonality in the baywide surveys, or in the prevalence of disease among tagged colonies. Similarly, there were no seasonal differences in the levels of Porites trematodiasis within Kaneohe Bay (Aeby 2007), or in the prevalence of coral diseases on the reefs of Tutuila, American Samoa (Aeby et al. 2009).

Increased water temperature is just one type of stress faced by corals and disease prevalence may be a reflection of the interaction between multiple stresses. For example, within Kaneohe Bay, water temperatures are higher during fall months (i.e. temperature stress) but water quality is impacted more during the rainy winter months when reefs experience increases in terrestrial runoff and sporadic sewage spills (i.e. reduced water quality). Interestingly, Williams et al. (2010), using a modeling approach, examined biotic and abiotic factors associated with coral disease (including MWS) on reefs surrounding Coconut Island within the southern end of Kaneohe Bay. For MWS, they found a positive association with both chlorophyll a concentrations (proxy for reduced water quality) and higher water temperatures, although chlorophyll a was a much stronger predictor variable. Separating out the influence of these different stressors on the infection rate or progression of MWS would require manipulative experiments, which are planned for future studies.

Onset of disease results from the complex interplay between host, pathogen and environment (Work et al. 2008) and it is still unclear which environmental variables may be affecting MWS processes. However, we observed that on some of the tagged colonies, MWS appeared to stop (no visual lesions) and then reappeared in subsequent months. After $2 \mathrm{yr}$, there were also portions of the formerly infected colonies that were disease free and had begun to regrow over old lesions. These observations suggest that something in the disease triad shifted through time, allowing some Montipora capitata colonies to recover from MWS.

The effects of the virulence of different diseases vary from mild impacts to complete mortality of colonies. For example, Yamashiro et al. (2000) found that Montipora growth anomalies resulted in the depletion of lipids, whereas significant colony mortality was reported from Acropora white syndrome (Aeby 2005,
Roff et al. 2006). In this study, we found that MWS produced slow, progressive tissue loss on tagged coral colonies, and substantial partial colony mortality on most colonies at the end of the yearlong study. Over a quarter of these colonies suffered complete mortality after $2 \mathrm{yr}$ of chronic disease. Among the coral diseases that cause tissue loss, MWS caused a much higher rate of loss $\left(3 \%\right.$ loss $\left.\mathrm{mo}^{-1}\right)$ than some diseases such as yellow band disease $\left(8 \%\right.$ loss $\mathrm{yr}^{-1}$; Bruckner \& Bruckner 2006) but lower rates than other diseases such as white band disease (up to $2 \mathrm{~cm} \mathrm{~d}^{-1}$; Antonius 1981, Gladfelter 1982, Peters 1993) or brown band disease $\left(1.2 \mathrm{~cm} \mathrm{~d}^{-1}\right.$; Haapkyla et al. 2009).

Experimental studies showed that MWS is directly transmissible, as all healthy coral fragments that were in contact with diseased fragments developed lesions, whereas none of the control fragments did. In the field, disease transmission from tagged colonies to neighboring colonies was also observed. These observations are consistent with the etiology of MWS being a communicable agent. None of the nontouching fragments within the aquaria developed lesions, suggesting that waterborne transmission is less effective than direct transmission. However, waterborne transmission should not be discounted at this time since characteristic signs of the disease appeared not only in colonies that were in direct contact with an infected individual but also in nearby colonies in the field.

Despite its low prevalence, MWS represents a slow, chronic source of mortality, and as such has the potential to negatively affect the reefs of Kaneohe Bay through time. MWS was first documented within the Bay in 2004. It is still present and has been affecting Montipora capitata colonies for many years. Disease is known to be a factor that structures communities in many different ecosystems (Harvell et al. 1999, 2002) including coral communities on other reefs. In the Florida Keys, USA, Acropora palmata, which was once a dominant shallow-water coral, has suffered an average Keyswide loss of $87 \%$ (Patterson et al. 2002). A. palmata is now on the endangered species list and disease has been implicated as the principal cause of its decline (Patterson et al. 2002).

MWS appears to exclusively affect Montipora capitata within Kaneohe Bay. In our monthly surveys of individual tagged colonies, we never observed similar disease signs in other coral genera, even in colonies that were directly touching MWS-infected M. capitata colonies. As such, MWS also has the potential to shift the coral community structure of the reefs within Kaneohe Bay towards coral species that are not susceptible to this disease. Differential disease susceptibility among coral genera has been found in a number of studies (Willis et al. 2004, Gochfeld et al. 2006, Aeby 2007, Vargas-Angel 2009), and individual coral dis- 
eases show variability in host specificity. For example, BBD has low host specificity and affects 19 Caribbean shallow-water coral species and 45 Indo-Pacific coral species (Sutherland et al. 2004), whereas white band disease only affects Acropora sp. in the Caribbean (Sutherland et al. 2004). Infection of the common reef coral Montipora capitata by MWS poses a potential risk to Hawaii's reefs. Recently, a disease outbreak with identical field signs as MWS within Kaneohe Bay, was documented on a reef in Maui that resulted in significant colony mortality and reduced coral cover (Ross et al. unpubl. data). Similarly, McClanahan (2004) reported that a disease outbreak almost eliminated Montipora from affected Kenyan reefs.

In summary, this is the first study examining the dynamics of MWS in Hawaii. MWS is a transmissible disease that is characterized by focal to multifocal lesions resulting in progressive tissue loss that can cause significant colony mortality. The disease has persisted on the reefs within Kaneohe Bay for the past several years, and recent outbreaks of a similar disease have been reported from other islands within Hawaii. Our findings suggest that MWS should be considered a disease of concern in Hawaii. Future work on the pathogenesis and etiology of MWS is needed to help develop management strategies to better ascertain its impact and potentially develop tools to manage it.

Acknowledgements. We thank the Hawaii Institute of Marine Biology for logistical support. The Hawaii Coral Reef Initiative Grant NOA06NOS4260200 provided partial funding. We also thank F. Cox, K. Rogers and F. Stanton for help with the field surveys. The manuscript was improved by comments from $\mathrm{F}$. Cox and F. Stanton.

\section{LITERATURE CITED}

Aeby GS (1991) Behavioral and ecological relationships of a parasite and its hosts within a coral reef system. Pac Sci 45: 263-269

Aeby GS (1992) The potential effect the ability of a coral intermediate host to regenerate may have had on the evolution of its association with a marine parasite. Proc 7 th Int Coral Reef Symp 2:809-815

Aeby GS (1998) A digenean metacercaria from the reef coral, Porites compressa, experimentally identified as Podocotyloides stenometra. J Parasitol 84:1259-1261

Aeby GS (2002) Trade-offs for the butterflyfish, Chaetodon multicinctus, when feeding on coral prey infected with trematode metacercariae. Behav Ecol Sociobiol 52:158-165

Aeby GS (2003) Corals in the genus Porites are susceptible to infection by a larval trematode. Coral Reefs 22:216

Aeby GS (2005) Outbreak of coral disease in the Northwestern Hawaiian Islands. Coral Reefs 24:481

Aeby GS (2006) Baseline levels of coral disease in the Northwestern Hawaiian Islands. Atoll Res Bull 543:471-488

Aeby GS (2007) Spatial and temporal patterns of infection of Porites trematodiasis on the reefs of Kaneohe Bay, Oahu, Hawaii. Bull Mar Sci 80:209-218
Aeby G, Work T, Fenner D, DiDonato E (2009) Coral and crustose coralline algae disease on the reefs of American Samoa. Proc 11th Int Coral Reef Symp 7:197-201

Akaike $H$ (1973) Information theory as an extension of the maximum likelihood principle. In: Petrov BN, Caski F (eds) Proc 2nd Int Symp on Information Theory. Akademiai Kiado, Budapest, p 261-281

Anderson RM, May RM (1979) Population biology of infectious diseases. Part I. Nature 280:361-367

Anderson MJ, Gorley RN, Clarke KR (2008) PERMANOVA+ for PRIMER: guide to software and statistical methods. PRIMER-E, Plymouth

Antonius A (1981) The 'band' diseases in coral reefs. Proc 4th Int Coral Reef Symp 2:7-14

Bak R (1983) Neoplasia regeneration and growth in the reefbuilding coral Acropora palmata. Mar Biol 77:221-227

Boyett HV, Bourne DG, Willis BL (2007) Elevated temperature and light enhance progression and spread of black band disease on staghorn corals of the Great Barrier Reef. Mar Biol 151:1711-1720

Bruckner AW, Bruckner RJ (1997a) The persistence of black band disease in Jamaica: impact on community structure. Proc 8th Int Coral Reef Symp 1:601-606

Bruckner AW, Bruckner RJ (1997b) Outbreak of coral disease in Puerto Rico. Coral Reefs 16:260

Bruckner AW, Bruckner RJ (2006) Consequences of yellow band disease (YBD) on Montastraea annularis (species complex) populations on remote reefs off Mona Island, Puerto Rico. Dis Aquat Org 69:67-73

Bruno JF, Selig ER, Casey KS, Page CA and others (2007) Thermal stress and coral cover as drivers of coral disease outbreaks. PLoS ONE 5:1-8

Carpenter KE, Abrar M, Aeby G, Aronson RB and others (2008) One third of reef-building corals face elevated extinction risk from climate change and local impacts. Science 321:560-563

Clarke KR, Somerfield PJ, Chapman MG (2006) On resemblance measures for ecological studies, including taxonomic dissimilarities and a zero-adjusted Bray-Curtis coefficient for denuded assemblages. J Exp Mar Biol Ecol 330:55-80

Cox EF, Ribes M, Kinzie RA III (2006) Temporal and spatial scaling of planktonic responses to nutrient inputs into a subtropical embayment. Mar Ecol Prog Ser 324:19-35

$>$ Edmunds P (1991) Extent and effect of black band disease on Caribbean reefs. Coral Reefs 10:161-165

Friedlander AM, Aeby G, Brainard R, Brown E and others (2008) The state of coral reef ecosystems of the Main Hawaiian Islands. In: Waddell J (ed) The state of coral reef ecosystems of the United States and Pacific Freely Associated States: 2008. NOAA Technical Memorandum NOS NCCOS 11. NOAA/NCCOS Center for Coastal Monitoring and Assessment, Biogeography Team, Silver Spring, MD

Gardner TA, Côté IM, Gill JA, Grant A, Watkinson AR (2003) Long-term region-wide declines in Caribbean corals. Science 301:958-960

Gil-Agudelo DL, Garzón-Ferreira J (2001) Spatial and seasonal variation of dark spots disease in coral communities of the Santa Marta area (Columbian Caribbean). Bull Mar Sci 69:619-629

Gladfelter W (1982) White-band disease in Acropora palmata: implications for the structure and growth of shallow reefs. Bull Mar Sci 32:639-643

> Gochfeld DJ, Olson JB, Slattery M (2006) Colony versus population variation in susceptibility and resistance to dark spot syndrome in the Caribbean coral Siderastrea siderea. Dis Aquat Org 69:53-65 
Green E, Bruckner A (2000) The significance of coral disease epizootiology for coral reef conservation. Biol Conserv 96: 347-361

Haapkyla J, Unsworth R, Seymour A, Melbourne-Thomas J, Flavell M, Willis B, Smith D (2009) Spatio-temporal coral disease dynamics in the Wakatobi Marine National Park, South-East Sulawesi, Indonesia. Dis Aquat Org 87: 105-115

> Harvell CD, Kim K, Burkholder JM, Colwell RR (1999) Emerging marine diseases-climate links and anthropogenic factors. Science 285:1505-1510

- Harvell CD, Mitchell CE, Ward JR, Altizer S, Dobson AP, Ostfeld RS, Samuel MD (2002) Climate warming and disease risks for terrestrial and marine biota. Science 296:2158-2162

Harvell CD, Jordan-Dahlgren E, Merkel S, Rosenberg E and others (2007) Coral disease, environmental drivers, and the balance between coral and microbial associates. Oceanography (Wash DC) 20:58-81

Hughes TP, Baird AH, Bellwood DR, Card M and others (2003) Climate change, human impacts, and the resilience of coral reefs. Science 301:929-933

Hunter C, Evans C (1995) Coral reefs in Kaneohe Bay, Hawaii: two centuries of western influence and two decades of data. Bull Mar Sci 57:501-515

> Hurvich CM, Tsai CL (1989) Regression and time-series model selection in small samples. Biometrika 76:297-307

Jokiel PL (1987) Ecology, biogeography and evolution of corals in Hawaii. Trends Evol Ecol 2:333-336

> Jones RJ, Bowyer J, Hoegh-Guldberg O, Blackall LL (2004) Dynamics of a temperature-related coral disease outbreak. Mar Ecol Prog Ser 281:63-77

Kaczmarsky LT, Draud M, Williams EH (2005) Is there a relationship between proximity to sewage effluent and the prevalence of coral disease? Caribb J Sci 41:124-137

Knowlton N (2001) The future of coral reefs. Proc Natl Acad Sci USA 98:5419-5425

Kuta KG, Richardson LL (2002) Ecological aspects of black band disease of corals: relationships between disease incidence and environmental factors. Coral Reefs 21:393-398

Lafferty K, Holt R (2003) How should environmental stress affect the population dynamics of disease? Ecol Lett 6: 654-664

Maragos J, Evans C, Holthus P (1985) Reef corals in Kaneohe Bay six years before and after termination of sewage discharges (Oahu, Hawaiian Archipelago). Proc 5th Int Coral Reef Congr 4:189-194

McClanahan TR (2004) Coral bleaching, diseases and mortality in the western Indian Ocean. In: Rosenberg E, Loya Y (eds) Coral health and disease. Springer-Verlag, Berlin

> Myers RL, Raymundo LJ (2009) Coral disease in Micronesian reefs: a link between disease prevalence and host abundance. Dis Aquat Org 87:97-104

Editorial responsibility: Garriet Smith, Aiken, South Carolina, USA
Page C, Willis B (2006) Distribution, host range and largescale spatial variability in black band disease prevalence on the Great Barrier Reef, Australia. Dis Aquat Org 69: $41-51$

Pandolfi JM, Jackson JB, Baron N, Bradbury RH and others (2005) Ecology. Are U.S. coral reefs on the slippery slope to slime? Science 307:1725-1726

Patterson KL, Porter JW, Ritchie KB, Polson SW and others (2002) The etiology of white pox, a lethal disease of the Caribbean elkhorn coral, Acropora palmata. Proc Natl Acad Sci USA 99:8725-8730

Peters E (1993) Diseases of other invertebrate phyla: Porifera, Cnidaria, Ctenophora, Annelida, Echinodermata. In: Couch J, Fournie J (eds) Pathobiology of marine and estuarine organisms. CRC Press, Boca Raton, FL, p 393-449

Poteet $M(2006)$ Shifting roles of abiotic and biotic regulation of a multi-host parasite following disturbance. In: Collinge S, Ray C (eds) Disease ecology: community structure and pathogen dynamics. Oxford University Press, New York, NY

Roff G, Hoegh-Guldberg, Fine M (2006) Intra-colonial response to Acroporid 'white syndrome' lesions in tabular Acropora spp. (Scleractinia). Coral Reefs 25:255-264

Sussman M, Willis B, Victor S, Bourne D (2008) Coral pathogens identified for white syndrome (WS) epizootics in the Indo-Pacific. PLoS ONE 3:e2393

Sutherland KP, Porter JW, Torres C (2004) Disease and immunity in Caribbean and Indo-Pacific zooxanthellate corals. Mar Ecol Prog Ser 266:273-302

Vargas-Angel B (2009) Coral health and disease assessment in the US Pacific remote island areas. Bull Mar Sci 84: 211-227

> Voss JD, Richardson LL (2006) Nutrient enrichment enhances black band disease progression in corals. Coral Reefs 25: 569-576

Ward J, Lafferty K (2004) The elusive baseline of marine disease: Are diseases in ocean ecosystems increasing? PLoS Biology 2:0542-0547

Williams GJ, Aeby GS, Cowie RO, Davy SK (2010) Predictive modeling of coral disease distribution within a coral reef system. PLoS ONE 5:e9264

Willis B, Page C, Dinsdale E (2004) Coral disease on the Great Barrier Reef. In: Rosenberg E, Loya Y (eds) Coral health and disease. Springer-Verlag, Berlin, p 69-104

- Work TM, Richardson LL, Reynolds TL, Willis BL (2008) Biomedical and veterinary science can increase our understanding of coral disease. J Exp Mar Biol Ecol 362: 63-70

Yamashiro H, Yamamoto M, van Woeski R (2000) Tumor formation on the coral Montipora informis. Dis Aquat Org 41: 211-217

Submitted: February 17, 2010; Accepted: May 25, 2010 Proofs received from author(s): July 9, 2010 